\title{
Color Analysis of Batik Fabric by Facile Smartphone Colorimetry
}

\author{
Yaowarat Sirisathitkul ${ }^{\mathrm{a}, 1}$, Suvita Kaewareelap ${ }^{\mathrm{b}, 2}$ \\ ${ }^{a}$ School of Engineering and Technology, Walailak University, Nakhon Si Thammarat, 80160, Thailand \\ ${ }^{b}$ School of Languages and General Education, Walailak University, Nakhon Si Thammarat, 80160, Thailand \\ Corresponding author: ${ }^{1}$ syaowara@mail.wu.ac.th, ${ }^{2}$ suvita_333@hotmail.com
}

\begin{abstract}
The color of a textile material is the first attribute and key component considered by consumers while purchasing cloth. However, measurement of fabric color is a very challenging task in the textile fabrication process. Colorimeters aids this measurement by adding objective assessments to a generally subjective process. The colorimeter application in Android smartphones provides a simple alternative to dedicated colorimetric devices. The purpose of this study was to determine the suitability of the smartphone colorimetry application for a Batik fabric color measurement. The colors of various Batik fabric images in the International Commission on Illumination $L^{*} a * b *$ color space, which includes all the colors that are visible by the human eye, obtained by a spectrophotometer and the colorimeter application were compared. Data of Batik fabric images acquired at three different distances of 10, 20, and $30 \mathrm{~cm}$ were analyzed. The color differences between the colorimeter and spectrophotometer results are various depending on the distance from the target. The $\Delta E^{*}{ }_{a b}$ and $\Delta E^{*}$ h metrics were used to evaluate the color differences between the reference and sample fabric colors. The lowest mean of $\Delta E_{a b}^{*}$ values was $12.11 \pm 5.29$ measured $20 \mathrm{~cm}$ away from each fabric. The mean values of $\Delta E_{a b}^{*}$ between pairs of color symbols from the Colorimeter application were comparable to those obtained by the spectrophotometer. The $\Delta E_{a b}^{*}$ values were more suitable for fabric color measurement than $\Delta E^{*}$. The results indicate that smartphone colorimetry provides reasonable accuracy, is simple to use for amateurs, suitable for fabric color matching, and can satisfy fabric market requirements.
\end{abstract}

Keywords - Color measurement; batik fabric; colorimeter; smartphone; CIE L*a*b*.

Manuscript received 28 Mar. 2020; revised 22 Jul. 2020; accepted 29 Oct. 2020. Date of publication 28 Feb. 2021. IJASEIT is licensed under a Creative Commons Attribution-Share Alike 4.0 International License.

\section{INTRODUCTION}

Batik is a famous fabric from Indonesia, which can be used for clothing, scarves, fashionable wall hangings, and household accessories. Since October 2, 2009, the United Nations Educational, Scientific, and Cultural Organization (UNESCO) acknowledges Batik as an intangible cultural heritage [1]. It is an ethnological object and traditional art form. The Batik fabrication process involves a traditional dyeing technique, in which melted wax is used to create exotic designs mostly on a natural fabric such as cotton and silk. The wax is applied to the fabric and left to dry; then, the fabric is dyed using cold water dyes. After the wax is removed, the covered part of the fabric retains its original color owing to the wax-resist dyeing.

Batik is a traditional art practiced by minorities of Southwest China. Yunnan Miao Batik is characterized by unique handicraft techniques and natural patterns [2]. In Malaysia, sarong clothing demonstrates a person's ethnic origin. Intricate designs have been created through the use of diverse motifs, colors, and motif patterns [3]. Batik Peranakan or Batik China (Chinese Batik) evolved through JavanesePeranakan-incorporated Chinese aesthetics primarily for the Peranakan Chinese market [4].

In Thailand, Batik is popular, particularly among the ThaiMuslims in the southern border provinces. It is recognized as a cultural heritage of the Thai-Muslims but has spread to other provinces across the country. Batik, with its design and process influenced by Indonesian and Malaysian culture, is produced as handicraft by households or medium-sized industrial factories.

Numerous Batik manufacturers in southern Thailand produce Batik color tones by estimation with the naked eye. They usually produce a set of uniform color tones, which rarely meet the designer's vision and fashion trends. In general, fashion designers in Batik select color tones using computer software such as Photoshop and Illustrator to specify the PANTONE standard color chart. They then communicate these color specifications to manufacturers. However, some local manufacturers or entrepreneurs do not 
have basic knowledge about the software or have limited access to standard color charts and colorimetric instruments.

In the textile industry, color is an essential parameter in clothing design and garment manufacturing. The color of a textile material is often the first attribute evaluated by consumers and a key component considered in the selection of fabrics. Colors are precisely measured in quality inspection to produce reproducible products [5]. In quality control, the product color should be a requirement.

The International Commission on Illumination (CIE) $L * a * b *$ color space is a specific organization of colors. It contains standardized chromatic color space values imitating the nonlinear responses of the human eye. This color space is considered perceptually uniform concerning the human color vision, which implies that it describes all colors visible by the human eye. The CIE $L^{*} a^{*} b^{*}$ expresses colors as three numerical values, where $L^{*}$ represents lightness and $a^{*}$ and $b^{*}$ are color components. The channel $L^{*}$ is in the range 0 to 100 corresponding to black to white. The color channel $a^{*}$ is in the range -128 to +127 corresponding to green to red. The color channel $b^{*}$ is in the range -128 to +127 corresponding to blue to yellow [5], [6].

Chroma is defined as colorfulness of an object in proportion to its brightness. With the increase in the level of illumination, the surface of a given chroma exhibits increasing colorfulness. The chroma is an attribute in the range 0 to 100 . The corresponding hue is a color and shade of a color. The hue angle is an attribute in the range 0 to 360 , commonly referred to as the pure spectrum of colors, from red, orange, yellow, green, cyan, blue, magenta, and back to red, so that red values correspond to both 0 and 360 .

A spectrophotometer provides color data using the widely accepted CIE $L * a * b *$ color space [7]. The CIE $L * a * b *$ color values have been successfully used to distinguish colors in various applications including resin composites [8], meat quality characteristics [9] and Pantone color and unused base inks [10]. Spectrophotometers are universally used in textile color determination (e.g., CIE $L^{*} a^{*} b^{*}$ data for melange fibre blends [11] and dye cotton fabrics [12]). The measurement data are also reported in terms of colorimetric values (CIE $\left.L^{*} a^{*} b^{*}\right)[13]$ and used to investigate different types of texture for textile samples [14].

The computer-controlled digital camera system DigiEye is used to measure color and provides colorimetric values (XYZ and CIE $L^{*} a^{*} b^{*}$ ) and spectral reflectance $R$ in the range of 400 to $700 \mathrm{~nm}$ [15]. This system has been utilized to measure the colors of printed fabrics [5] and cotton raw materials [16]. The color measurements by a spectrophotometer and DigiEye have a statistically significant correlation. However, differences exist between the spectral reflectance curves and colors (more than ten units [7]). The spectrophotometer and DigiEye have a robust correlation between the coordinates of solid colors of fabrics [17].

Specialized colorimeter devices, including DigiEye and spectrophotometer, are relatively expensive and not widely available. Smartphones provide low-cost, widely available alternatives. Such devices have high processing capabilities, built-in high-resolution sensors, and high-quality digital cameras. These specifications make them practical for numerous tasks [18]-[21]. Some built-in smartphone functions have been implemented for colorimetric analyses.
In agriculture and farming, the standard citrus color index of oranges [22] and soil colors [23], [24] have been analyzed and compared against the standard color chart. The application has also been extended to determine the level of chlorine concentration in water [25]. In fashion, the colors of the user's skin and hair have been automatically calculated and analyzed for each person [26]. In the textile industry, the woven fabric density has been measured by a portable setup, instead of conventional desktop instruments [27].

Colorimetric applications for iPhone operating systems (IOSs) and Android smartphones can be used to analyze the color values of samples. Currently, available smartphone applications such as Catch Color, Colorimeter, and Color Detector provide simple and less expensive color measurements than spectrophotometers with user-friendly interfaces. The ColorMeter RGB Colorimeter application on the IOS has been used to objectify the color matching of a silicone maxillofacial prosthesis [28]. The Color Lab and ON Color Measure applications on Android devices for image analysis quantified the magnetic textile solid-phase extractions of colored compounds [29]. The application Colorimeter has been implemented in fine-paste ware color classification [30]. The application Color Picker has been used in colorimetric detection of urine glucose [31] and forensic saliva sample screening [32]. Smartphone applications have also been used in colorimetric detection for paper-based glucose assays (Color Grab) [33] and food analyses (RGB) [34].

Use of smartphones for Batik fabric color measurements has not been reported. This study aimed to determine the suitability of the application Colorimeter as an objective aid in the matching of the color shade of the Batik fabric and development of fabric color measurement systems.

\section{MATERIAL AND MethoD}

\section{A. Colorimeter Application}

The application Colorimeter (Research Lab Tools) for Android devices costs only \$0.99 in Google Play Store; hence, millions of smartphone users use it globally. The application Colorimeter (Fig. 1) provides the color parameters in Moment1, Moment2, and real-time visible spectra (400-700 $\mathrm{nm})$. Moment1 shows CIE $L^{*} a^{*} b^{*}$, chroma, hue, red-greenblue (RGB), and color names, whereas Moment2 compares the result to the last measured color [35].

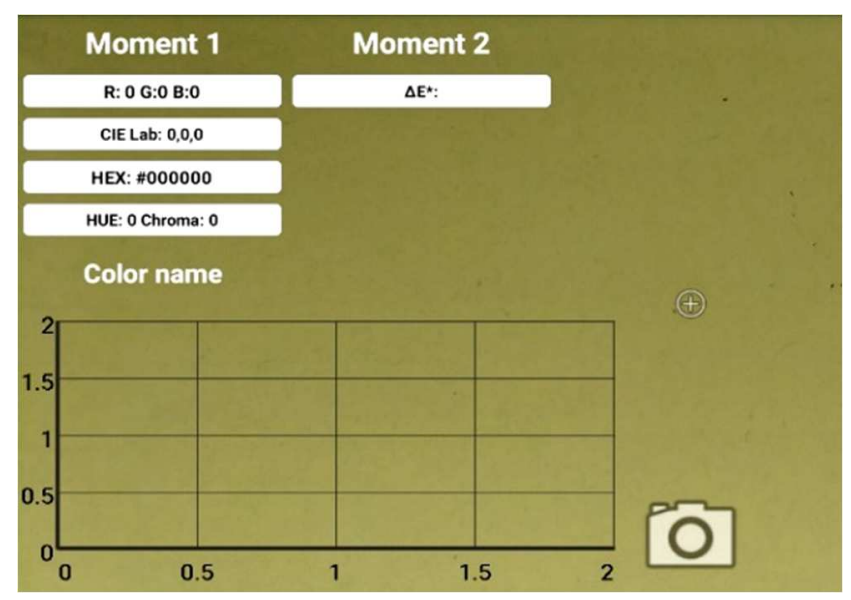

Fig. 1 The Colorimeter application interface 


\section{B. Batik Fabric Samples}

A wide range of colors of fabrics was selected from the collection of a local manufacturer. The measurements of

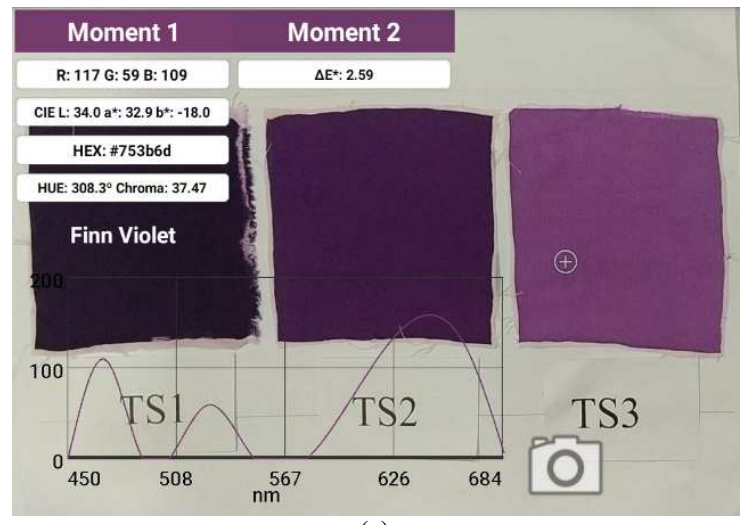

(a)

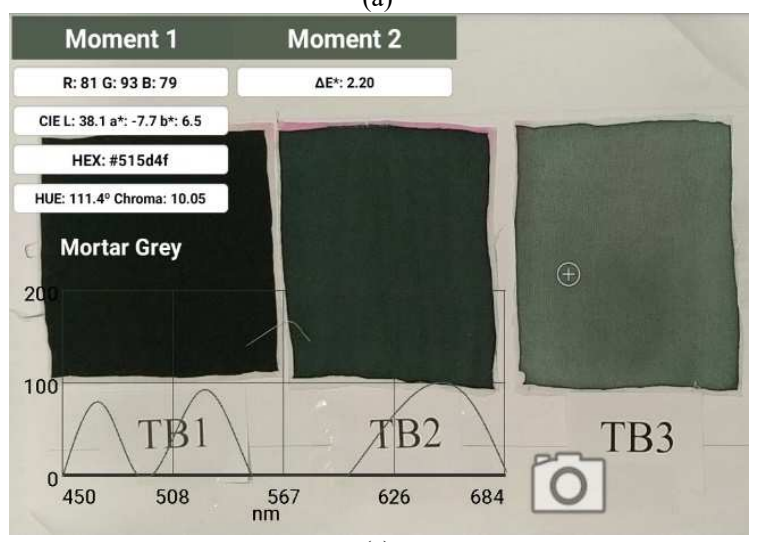

(c)

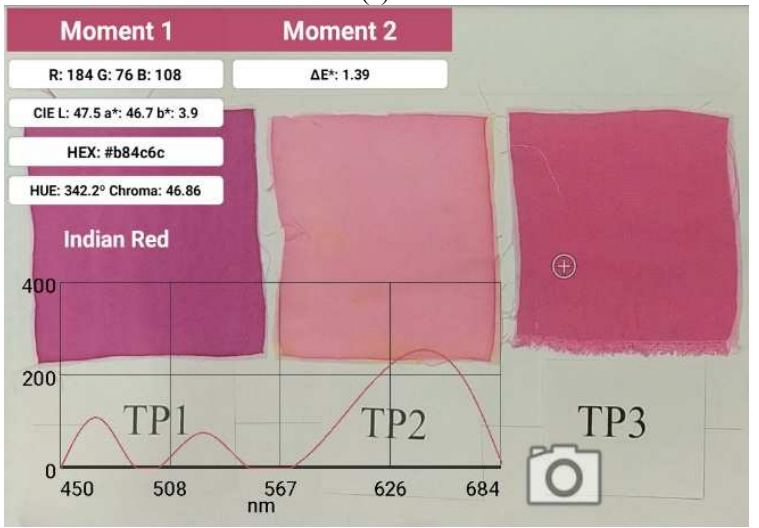

(e) identical or similar colors were performed on 19 reference fabric color samples in seven color groups (Fig. 2) and eight Batik fabric samples in seven color groups (Fig. 3). Each color group contained 2-4 fabric color shades.

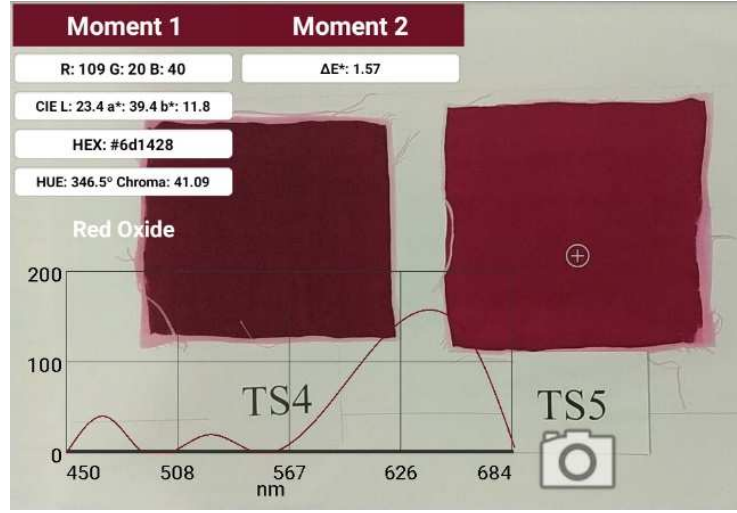

(b)

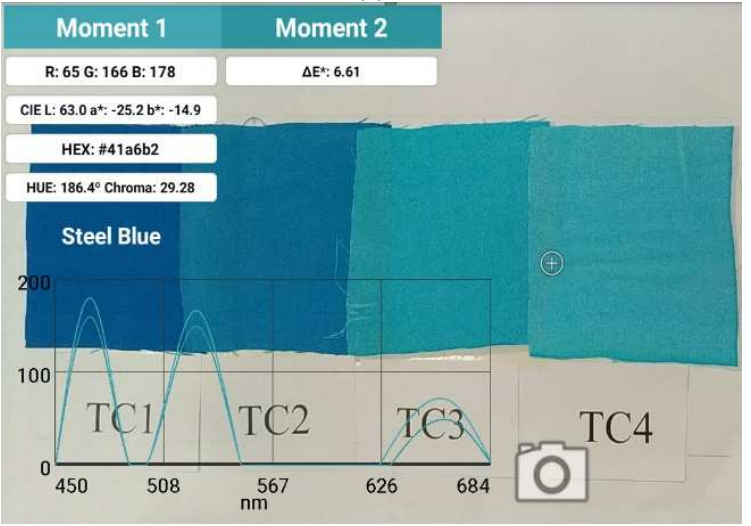

(d)

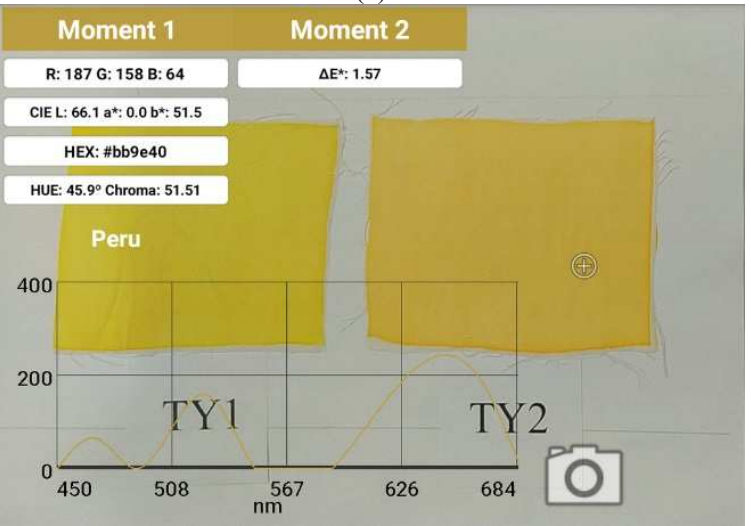

(f)

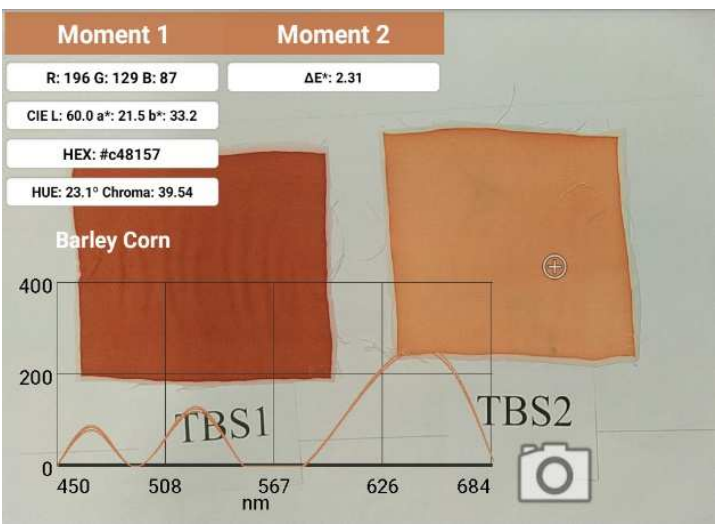

(g)

Fig. 2 The reference fabric color samples in 7 color groups (a) purple (TS1-TS3), (b) red (TS4-TS5), (c) grey (TB1-TB3), (d) blue (TC1-TC4), (e) pink (TP1TP3), (f) yellow (TY1-TY2) and (g) brown (TBS1-TBS2) 

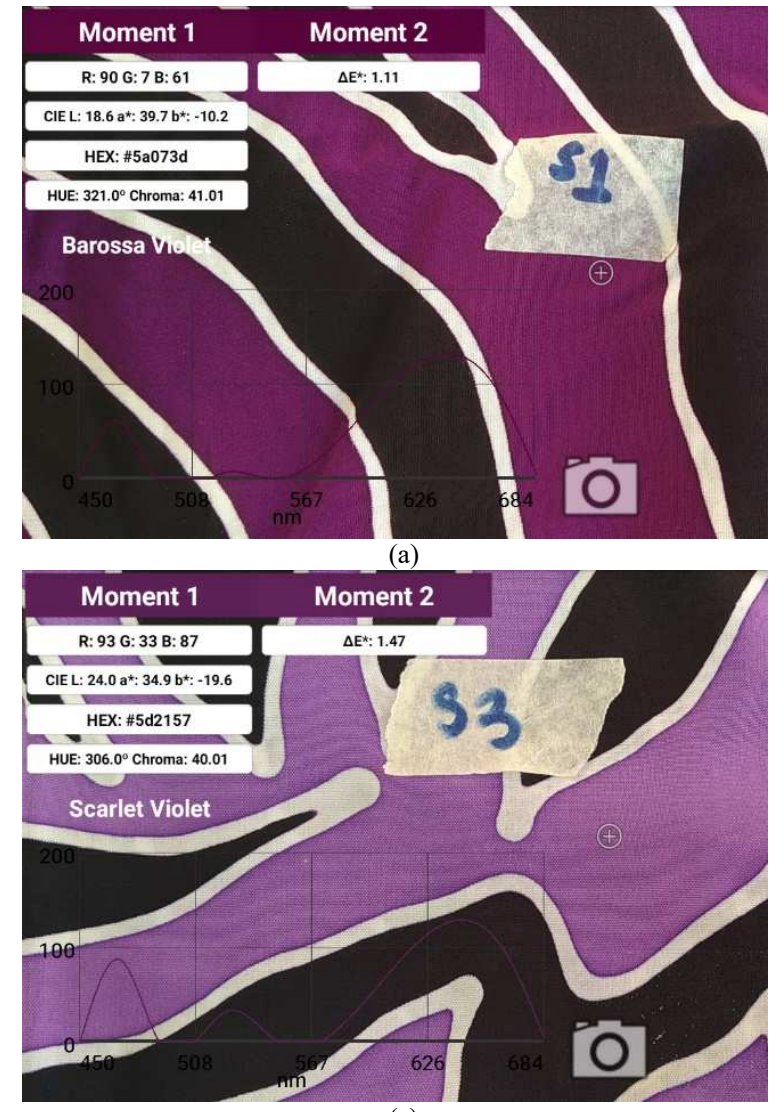

(c)

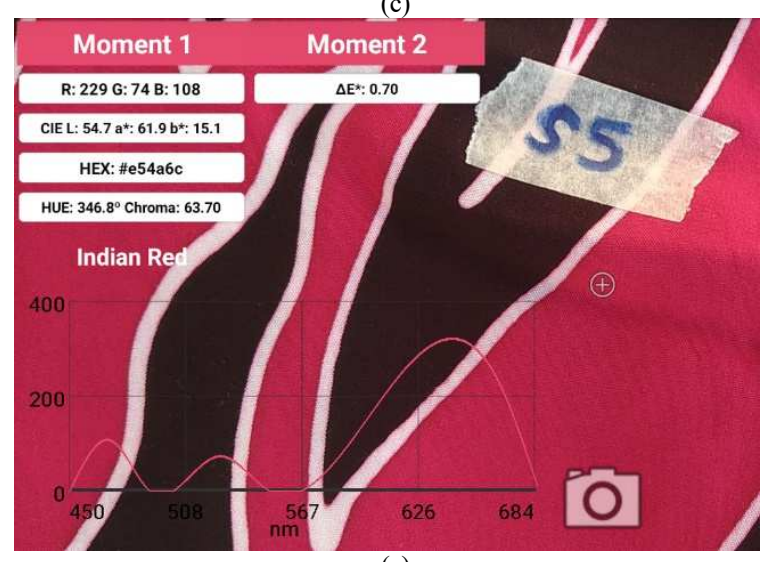

(e)

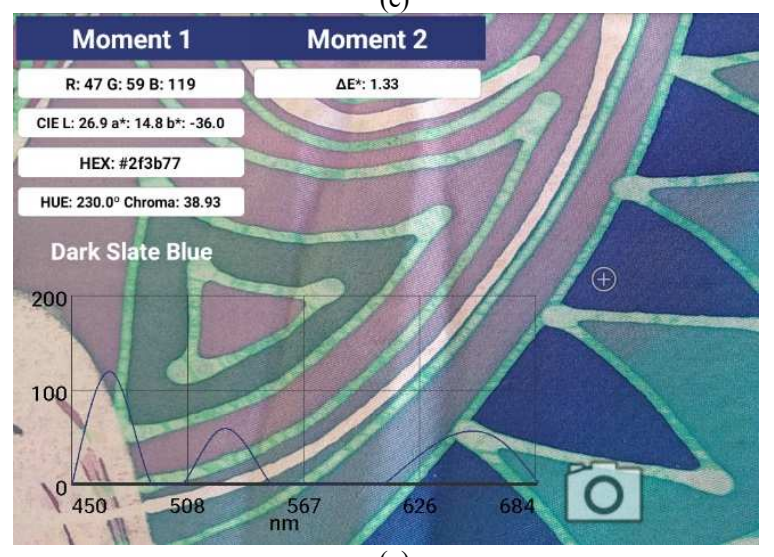

(g)

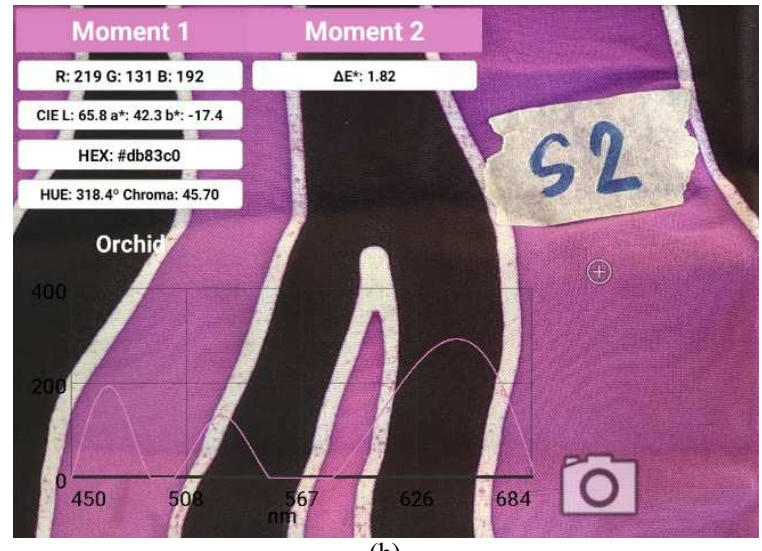

(b)

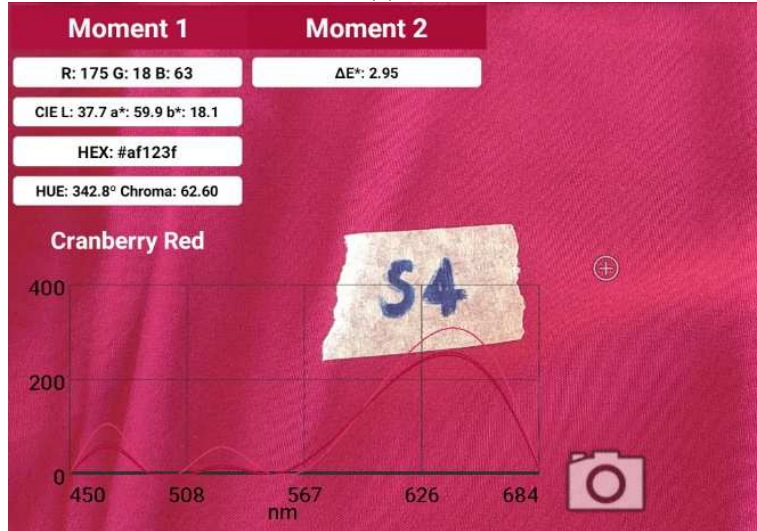

(d)
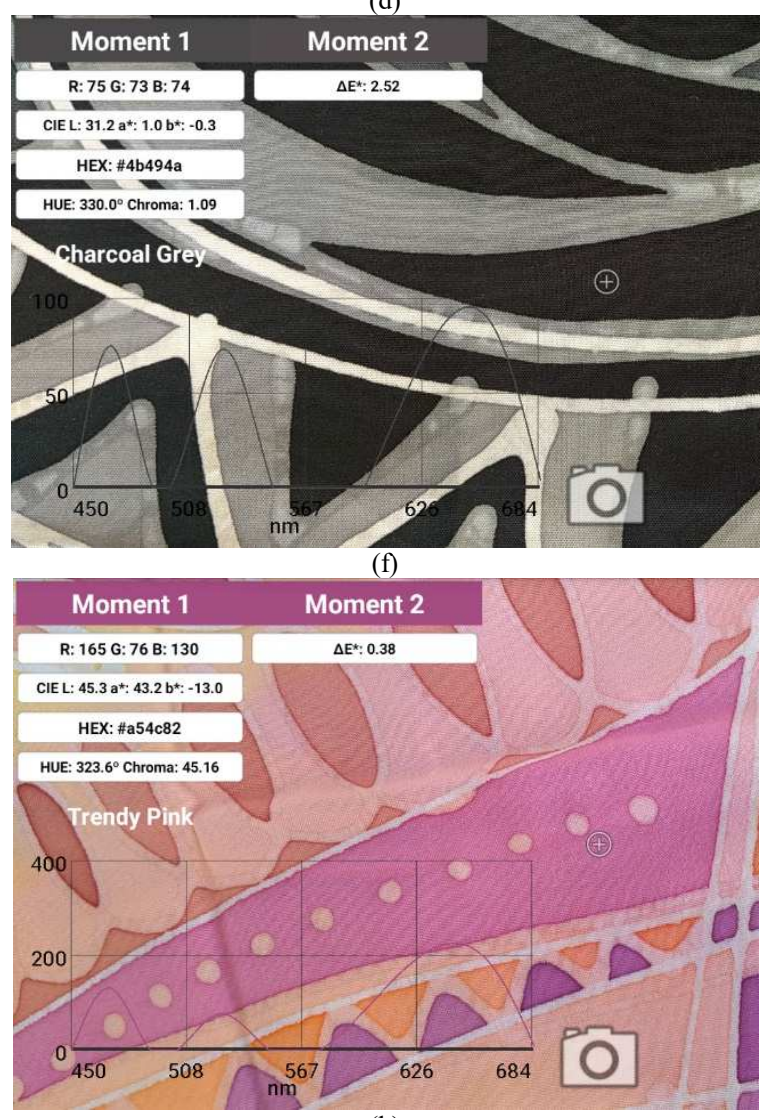

(h)

Fig. 3 Batik fabric samples in 7 color groups: purple (a) S1, (b) S2, (c) S3; red (d) S4, (e) S5; grey (f) B1-B3; blue (g) C1-C4; pink, yellow and brown (h) P1$\mathrm{P} 3, \mathrm{Y} 1-\mathrm{Y} 2$ and BS1 -BS2 
TABLE I

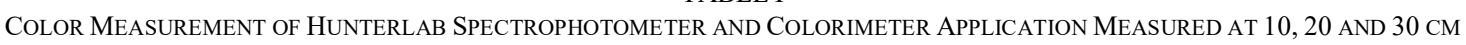

\begin{tabular}{|c|c|c|c|c|c|c|c|c|c|c|c|c|c|c|c|c|c|c|c|}
\hline \multirow{2}{*}{$\begin{array}{l}\text { Color } \\
\text { group }\end{array}$} & \multirow{2}{*}{ Symbol } & \multicolumn{3}{|c|}{ Spectrophotometer } & \multicolumn{5}{|c|}{ Colorimeter Application $(10 \mathrm{~cm})$} & \multicolumn{5}{|c|}{ Colorimeter Application $(20 \mathrm{~cm})$} & \multicolumn{5}{|c|}{ Colorimeter Application $(30 \mathrm{~cm})$} \\
\hline & & $L^{*}$ & $a^{*}$ & $b^{*}$ & $L^{*}$ & $a^{*}$ & $b^{*}$ & Chroma & Hue & $L^{*}$ & $a^{*}$ & $b^{*}$ & Chroma & Hue & $L^{*}$ & $a^{*}$ & $b^{*}$ & Chroma & Hue \\
\hline \multirow{7}{*}{ Purple } & TS1 & 18.57 & 25.27 & -18.92 & 17.87 & 41.33 & -17.03 & 45 & 313 & 17.13 & 31.23 & -9.23 & 33 & 322 & 18.37 & 33.47 & -13.87 & 36 & 315 \\
\hline & TS2 & 22.62 & 27.18 & -24.61 & 25.73 & 45.37 & -22.37 & 51 & 309 & 23.40 & 46.37 & -19.67 & 50 & 312 & 21.83 & 40.70 & -21.37 & 46 & 307 \\
\hline & TS3 & 42.19 & 23.4 & -26.25 & 40.60 & 43.57 & -25.77 & 51 & 304 & 42.97 & 42.37 & -22.00 & 48 & 310 & 41.93 & 38.90 & -32.47 & 51 & 287 \\
\hline & $\mathrm{S} 1$ & 17.93 & 23.08 & -18.06 & 21.83 & 41.90 & -18.00 & 46 & 313 & 19.77 & 40.53 & -9.97 & 42 & 322 & 18.87 & 40.83 & -13.10 & 43 & 318 \\
\hline & $\mathrm{S} 2$ & 26.93 & 29.34 & -26.4 & 18.40 & 40.67 & -24.30 & 47 & 302 & 30.70 & 45.60 & -23.27 & 51 & 309 & 25.17 & 46.83 & -27.63 & 54 & 303 \\
\hline & S3 & 47.25 & 25.22 & -25.08 & 50.07 & 40.23 & -29.53 & 50 & 295 & 43.33 & 41.97 & -30.67 & 52 & 294 & 40.90 & 32.57 & -23.67 & 40 & 295 \\
\hline & TS4 & 23.94 & 39.6 & -2.4 & 23.87 & 46.53 & 21.37 & 51 & 346 & 21.73 & 42.33 & 5.60 & 43 & 337 & 22.67 & 39.90 & 12.77 & 42 & 346 \\
\hline \multirow{3}{*}{ Red } & TS5 & 26.67 & 45.16 & 3.34 & 24.67 & 47.90 & 12.67 & 50 & 339 & 29.63 & 53.27 & 24.50 & 59 & 345 & 28.83 & 49.73 & 19.40 & 53 & 346 \\
\hline & $\mathrm{S} 4$ & 22.98 & 36.89 & -0.77 & 27.90 & 51.53 & 15.93 & 54 & 341 & 23.13 & 46.47 & 5.47 & 47 & 334 & 22.87 & 40.33 & 13.03 & 42 & 346 \\
\hline & S5 & 28.74 & 46.33 & -0.6 & 27.73 & 50.97 & 20.63 & 55 & 344 & 35.23 & 58.47 & 23.63 & 63 & 345 & 33.17 & 57.90 & 15.13 & 60 & 338 \\
\hline \multirow{6}{*}{ Grey } & TB1 & 14.78 & 0.66 & -1.41 & 17.60 & 2.63 & 2.97 & 4 & 17 & 13.10 & 2.07 & -3.60 & 4 & 255 & 11.03 & 0.23 & 1.90 & 2 & 40 \\
\hline & TB2 & 29.3 & -1.96 & -1.43 & 31.43 & 2.67 & 4.80 & 5 & 23 & 31.23 & 5.47 & -9.50 & 11 & 253 & 25.43 & 3.90 & -9.57 & 10 & 240 \\
\hline & TB3 & 47.31 & -2.34 & -1.1 & 53.90 & 0.73 & 1.50 & 2 & 32 & 50.13 & 4.70 & -0.17 & 5 & 344 & 51.00 & -5.00 & 1.37 & 5 & 148 \\
\hline & $\mathrm{B} 1$ & 15.41 & 2.2 & -2.09 & 13.17 & 3.27 & 2.20 & 4 & 8 & 15.60 & 3.90 & -3.57 & 5 & 285 & 10.23 & 2.57 & 1.20 & 3 & 4 \\
\hline & B2 & 31.8 & -1.03 & -3.9 & 33.10 & 0.73 & 2.47 & 3 & 24 & 30.83 & 2.60 & -1.53 & 3 & 313 & 27.73 & 2.73 & -2.70 & 4 & 283 \\
\hline & B3 & 50.97 & -1.99 & -3.9 & 51.60 & 1.17 & 4.93 & 5 & 32 & 49.57 & 3.37 & -0.03 & 3 & 341 & 50.20 & 0.17 & -1.17 & 4 & 179 \\
\hline \multirow{8}{*}{ Blue } & $\mathrm{TC} 1$ & 38.74 & -7.38 & -30.71 & 40.20 & -9.77 & -28.80 & 30 & 197 & 40.70 & -3.27 & -36.20 & 36 & 202 & 42.23 & 0.23 & -41.70 & 42 & 204 \\
\hline & TC2 & 53.85 & -17.89 & -26.95 & 59.17 & - & -29.33 & 31 & 201 & 51.73 & -11.90 & -26.03 & 29 & 199 & 44.73 & -0.73 & -39.43 & 39 & 207 \\
\hline & TC3 & 58.78 & -26.55 & -24.86 & 56.73 & - & -10.00 & 27 & 183 & 57.13 & -23.47 & -19.90 & 31 & 189 & 61.70 & -17.67 & -28.07 & 33 & 195 \\
\hline & TC4 & 69.8 & -20.2 & -13.81 & 72.43 & - & -17.27 & 30 & 189 & 69.57 & -19.63 & -23.87 & 31 & 194 & 61.50 & -18.53 & -26.53 & 33 & 195 \\
\hline & $\mathrm{C} 1$ & 42.2 & -12.17 & -35.49 & 41.03 & 0.73 & -40.63 & 41 & 206 & 42.50 & 4.47 & -45.10 & 45 & 209 & 43.20 & 5.47 & -46.53 & 47 & 209 \\
\hline & $\mathrm{C} 2$ & 52.2 & -17.1 & -32.2 & 52.87 & - & -24.13 & 28 & 197 & 54.17 & -19.80 & -24.07 & 31 & 192 & 47.60 & -6.17 & -37.77 & 38 & 201 \\
\hline & $\mathrm{C} 3$ & 67.67 & -27.74 & -23.74 & 67.60 & - & -14.87 & 38 & 182 & 67.60 & -28.73 & -20.40 & 35 & 187 & 55.60 & -13.37 & -32.70 & 35 & 198 \\
\hline & $\mathrm{C} 4$ & 72.41 & -24.26 & -21.54 & 72.33 & - & -21.00 & 26 & 197 & 72.20 & -12.50 & -20.87 & 24 & 199 & 67.93 & -19.43 & -33.80 & 39 & 195 \\
\hline \multirow{6}{*}{ Pink } & TP1 & 55.87 & 35.12 & -9.03 & 48.57 & 48.53 & -10.07 & 50 & 328 & 50.30 & 50.03 & -8.37 & 51 & 330 & 49.53 & 52.73 & -24.47 & 58 & 313 \\
\hline & TP2 & 66.55 & 25.25 & -6.08 & 66.87 & 18.90 & -3.30 & 20 & 335 & 71.87 & 28.10 & 3.93 & 28 & 349 & 69.93 & 31.83 & -16.10 & 36 & 313 \\
\hline & TP3 & 51.98 & 36.56 & -5.46 & 52.50 & 44.00 & 2.87 & 44 & 342 & 55.07 & 38.03 & -8.17 & 39 & 330 & 50.77 & 48.37 & -11.67 & 50 & 327 \\
\hline & $\mathrm{P} 1$ & 51.88 & 39.46 & -15.67 & 46.43 & 43.70 & -15.90 & 49 & 330 & 50.90 & 52.57 & -7.63 & 53 & 331 & 57.87 & 53.10 & -29.33 & 61 & 308 \\
\hline & $\mathrm{P} 2$ & 73.36 & 28.62 & -8.38 & 75.23 & 19.80 & -2.43 & 20 & 337 & 71.50 & 29.80 & -2.87 & 28 & 348 & 59.90 & 29.70 & -16.20 & 34 & 310 \\
\hline & P3 & 55.92 & 44.46 & -6.53 & 56.77 & 43.43 & -5.43 & 44 & 334 & 50.23 & 42.80 & -14.80 & 45 & 321 & 52.27 & 43.37 & -12.13 & 45 & 325 \\
\hline \multirow{4}{*}{ Yellow } & TY1 & 75.53 & -5.46 & 52.07 & 77.37 & -4.67 & 29.80 & 30 & 51 & 76.20 & -1.97 & 42.47 & 43 & 46 & 83.60 & -6.93 & 43.33 & 44 & 52 \\
\hline & TY2 & 75.98 & 5.37 & 46.96 & 84.03 & -1.30 & 31.40 & 31 & 45 & 79.80 & 4.07 & 27.30 & 28 & 36 & 76.17 & -5.63 & 34.97 & 35 & 51 \\
\hline & Y1 & 83.92 & 0.8 & 56.26 & 75.50 & -0.63 & 22.17 & 22 & 45 & 76.73 & -5.80 & 43.23 & 44 & 51 & 77.90 & -6.93 & 39.77 & 40 & 53 \\
\hline & Y2 & 82.3 & 6.9 & 42.84 & 82.30 & 0.20 & 25.20 & 25 & 42 & 75.37 & -1.13 & 22.73 & 34 & 42 & 82.13 & 0.03 & 38.70 & 39 & 43 \\
\hline \multirow{4}{*}{ Brown } & TBS1 & 48.56 & 29.1 & 26.82 & 48.73 & 33.53 & 33.30 & 47 & 15 & 47.77 & 32.60 & 33.43 & 47 & 16 & 44.97 & 25.43 & 17.67 & 31 & 8 \\
\hline & TBS2 & 71.58 & 24.66 & 25.42 & 70.73 & 15.37 & 30.37 & 34 & 26 & 70.13 & 19.30 & 22.87 & 30 & 18 & 62.30 & 20.00 & 14.83 & 25 & 10 \\
\hline & BS1 & 47.89 & 32.65 & 30.61 & 47.90 & 30.37 & 25.87 & 40 & 12 & 47.13 & 31.67 & 25.47 & 41 & 11 & 46.87 & 35.77 & 14.57 & 29 & 9 \\
\hline & BS2 & 69.61 & 22.93 & 24.45 & 69.33 & 15.33 & 21.67 & 27 & 21 & 68.40 & 17.97 & 29.97 & 35 & 24 & 69.00 & 16.27 & 17.27 & 24 & 16 \\
\hline
\end{tabular}




\section{Data Analysis}

The fabric colors were assessed using the application Colorimeter installed on an Android smartphone (Oppo A5 2020) and HunterLab MiniScan $\AA$ EZ spectrophotometer. The smartphone was used to photograph all fabrics under indirect normal daylight conditions for indoor inspection. As the smartphone is a non-contact measurement device, all color measurements for each fabric were carried out at three distances $(10,20$, and $30 \mathrm{~cm})$. The HunterLab MiniScan ${ }^{\circledR}$ EZ spectrophotometer is a portable and versatile color measurement instrument. This spectrophotometer was used by touching its viewing area with the fabric. In both cases, the color measurements for each fabric were replicated three times to obtain an average value. The arithmetic means of the CIE colorimetric values, $L^{*} a^{*} b^{*}$, were obtained using both HunterLab spectrophotometer and application Colorimeter. The arithmetic means of other colorimetric values (hue, chroma, and RGB) were calculated using the application Colorimeter.

One of the most critical textile quality assessments is the determination of color differences. The color differences between the reference fabric color samples and Batik fabric samples were evaluated using CIELAB $\left(\Delta E^{*}{ }_{a b}\right)$ and CIELCH $\left(\Delta E_{c h}^{*}\right)$ [36]. For an appropriate comparison, the differences in $L^{*} a^{*} b^{*}$, hue, and chroma values between the two measuring instruments were computed. In both cases, small color differences $\left(\Delta E^{*}{ }_{a b}, \Delta E^{*}{ }_{c h}\right)$ indicate a closer color match. $\Delta E^{*}{ }_{a b}$ and $\Delta E^{*}$ ch were calculated by

$$
\Delta E_{a b}^{*}=\sqrt{\left(\Delta L^{*}\right)^{2}+\left(\Delta a^{*}\right)^{2}+\left(\Delta b^{*}\right)^{2}}
$$

Where,

$\Delta L^{*}$ is the lightness difference

$\Delta a^{*}$ is the red/green difference

$\Delta b^{*}$ is the yellow/blue difference

$$
\Delta E_{c h}^{*}=\sqrt{\left(\Delta L^{*}\right)^{2}+\left(\Delta C^{*}\right)^{2}+\left(\Delta H^{*}\right)^{2}},
$$

Where,

$\Delta L^{*}$ is the lightness difference

$\Delta C^{*}$ is the chroma difference

$\Delta H^{*}$ is the hue difference

\section{RESULTS AND DISCUSSION}

\section{A. Performance of the Application Colorimeter for the Fabric Samples}

Table 1 shows the color measurements by the HunterLab spectrophotometer and application Colorimeter at 10,20, and $30 \mathrm{~cm}$. The visual colors were classified into seven groups (purple, red, grey, blue, pink, yellow, and brown). For the yellow and brown color groups, the color measurement by Colorimeter led to the color direction in the color coordinates $\left(a^{*}, b^{*}\right)$ with a dominant value in $+b^{*}$, indicating that the color strength of the sample was yellowish [15]. For the purple, red, and pink color groups, the color measurement by Colorimeter led to the color direction in the color coordinates $\left(a^{*}, b^{*}\right)$ with a dominant value in $+a^{*}$, corresponding to a reddish color strength of the sample. For the blue color group, the color measurement by Colorimeter led to the color direction in the color coordinates $\left(a^{*}, b^{*}\right)$ with a dominant value in $-b^{*}$, corresponding to a bluish color strength.

Lightness $\left(L^{*}\right)$ is the dominant value for the grey color group because grey is composed of black and white. Thus, the most grey colors are mixed with a small number of color coordinates $\left(a^{*}, b^{*}\right)$ leading to variations in $a^{*}$ and $b^{*}$. For the purple and grey color groups, the dark color of each fabric group led to the lowest lightness level $\left(L^{*}\right)$. The hue values for the six color groups except the grey color group corresponded to the hue angles in the CIE chromaticity diagram and this indicates that the hue values were statistically related to the colors of the samples.

To evaluate the accuracy and satisfaction of Colorimeter, we computed the color differences between Colorimeter and the HunterLab spectrophotometer. Table 2 compares the means of $\Delta E_{a b}^{*}$ obtained by the two instruments for each color group. All color parameters measured by Colorimeter were close to those measured by the spectrophotometer. The lowest mean $\Delta E_{a b}^{*}$ values were obtained for the samples of the grey color groups, 7.07, 5.89, and 5.06 at the distances of 10, 20, and $30 \mathrm{~cm}$, respectively. The largest differences between the two measuring instruments were observed for the purple, red, and yellow color groups (more than ten units for all three distances). The lowest mean of $\Delta E^{*}{ }_{a b}$ was $12.11 \pm 5.29$, measured at $20 \mathrm{~cm}$ away from each fabric.

TABLE II

Statistical Analysis of Color Difference $\left(\Delta E^{*} a b\right)$ Between the Measured Values by Hunterlab Spectrophotometer and Colorimeter APPLICATION AT 10, 20 AND 30 CM

\begin{tabular}{ccccccc}
\hline $\begin{array}{c}\text { Distance from target } \\
\text { Color group }\end{array}$ & \multicolumn{2}{c}{$\mathbf{1 0} \mathbf{~ c m}$} & \multicolumn{2}{c}{$\mathbf{~ c m}$} & \multicolumn{3}{c}{$\mathbf{3 0} \mathbf{~ c m}$} \\
\cline { 2 - 7 } & Mean & SD & Mean & SD & Mean & SD \\
\hline Purple & 17.41 & 2.27 & 17.52 & 3.15 & 14.36 & 3.90 \\
Red & 19.80 & 6.70 & 17.72 & 9.12 & 16.58 & 2.53 \\
Grey & 7.07 & 1.65 & 5.89 & 3.30 & 5.06 & 2.46 \\
Blue & 9.56 & 3.93 & 9.12 & 4.82 & 16.34 & 4.65 \\
Pink & 8.81 & 4.67 & 10.58 & 4.76 & 15.45 & 6.14 \\
Yellow & 23.78 & 7.76 & 17.33 & 5.42 & 13.87 & 4.89 \\
Brown & 7.94 & 2.17 & 6.61 & 1.10 & 12.88 & 3.22 \\
Mean & $\mathbf{1 3 . 4 8}$ & & $\mathbf{1 2 . 1 1}$ & & $\mathbf{1 3 . 5 1}$ & \\
SD & $\mathbf{8 . 0 3}$ & & $\mathbf{5 . 2 9}$ & & $\mathbf{3 . 9 5}$ & \\
\hline
\end{tabular}




\section{B. Color Differences between the Reference Batik Fabric Samples and Batik Fabric Samples}

The color differences may be evaluated using either CIE $L^{*} a^{*} b^{*}$ or CIEDE2000 formulas [29], [37]. In this study, $\Delta E^{*}{ }_{a b}$ and $\Delta E^{*}{ }_{c h}$ were used to evaluate the color differences, because this is a widely used and is a comparatively simple system. The color difference values $\left(\Delta E_{a b}^{*}\right)$ between the reference fabric color samples and Batik fabric samples, obtained using the HunterLab spectrophotometer and Colorimeter, are presented in Table 3. For Colorimeter, the $\Delta E_{c h}^{*}$ values were also calculated for the color measurement.

The small color value of $\Delta E_{a b}^{*}$ suggests the minimal difference between the visual inspections. As shown in Table 3 , the mean of $\Delta E_{a b}^{*}$ for the HunterLab spectrophotometer was $6.05 \pm 2.70$. Suppose the acceptability threshold is the mean of $\Delta E_{a b}^{*}$ values, $\Delta E_{a b}^{*} \geq 6.05$. This value implies some differences between the colors of the samples. Therefore, some differences existed between the reference fabric color samples and Batik fabric samples for the blue, pink, and yellow color groups.

The color difference $\Delta E_{a b}^{*}$ values of Colorimeter were $8.49 \pm 3.31,7.30 \pm 2.90$ and $7.69 \pm 2.76$ at 10,20 and $30 \mathrm{~cm}$, respectively. These values were similar to those of the HunterLab spectrophotometer. The lowest mean of $\Delta E^{*}{ }_{a b}$ was obtained at $20 \mathrm{~cm}(7.30 \pm 2.90)$. Assuming an acceptability threshold value by 7.30, some differences existed between the reference fabric color samples and Batik fabric samples for the blue, pink, and yellow color groups.

The color difference $\Delta E_{c h}^{*}$ values of Colorimeter were 8.57 $\pm 3.45,11.84 \pm 13.47$ and $12.55 \pm 11.44$ at 10,20 and $30 \mathrm{~cm}$, respectively. The largest $\Delta E_{c h}^{*}$ values were obtained for the grey color groups because the hue represents the primary colors and distinguishes one color from another and this implies that the color difference $\left(\Delta E_{c h}^{*}\right)$ can be used for a color measurement except for the grey color.

According to the analyses, the smartphone colorimetry can be applied for Batik color measurements. It provides the classification in the CIE $L^{*} a^{*} b^{*}$ color space. The presented results show that the colors obtained by Colorimeter and the HunterLab spectrophotometer are in agreement. However, visible differences existed between the color coordinates. Such differences could be attributed to the pixel choice in the smartphone colorimetry.

TABLE III

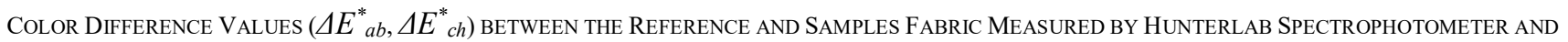
COLORIMETER APPLICATION

\begin{tabular}{|c|c|c|c|c|c|c|c|c|}
\hline \multirow{2}{*}{$\begin{array}{l}\text { Color } \\
\text { group }\end{array}$} & \multirow[t]{2}{*}{ Symbol } & \multirow{2}{*}{$\begin{array}{c}\Delta E^{*}{ }_{a b} \text { from } \\
\text { HunterLab } \\
\text { spectrophotometer }\end{array}$} & \multicolumn{3}{|c|}{$\begin{array}{c}\Delta E_{a b}^{*} \text { from Colorimeter } \\
\text { application }\end{array}$} & \multicolumn{3}{|c|}{$\begin{array}{c}\Delta E_{c h}^{*} \text { from Colorimeter } \\
\text { application }\end{array}$} \\
\hline & & & $10 \mathrm{~cm}$ & $20 \mathrm{~cm}$ & $30 \mathrm{~cm}$ & $10 \mathrm{~cm}$ & $20 \mathrm{~cm}$ & $30 \mathrm{~cm}$ \\
\hline \multirow{3}{*}{ Purple } & TS1 - S1 & 2.4382 & 4.1218 & 9.6934 & 7.4233 & 4.1316 & 9.5667 & 7.2572 \\
\hline & TS2 - S2 & 5.1425 & 8.9221 & 8.1754 & 9.3808 & 10.8407 & 8.0648 & 10.1625 \\
\hline & $\mathrm{TS} 3-\mathrm{S} 3$ & 5.5031 & 10.7199 & 8.6836 & 10.8912 & 13.4772 & 16.7065 & 13.1891 \\
\hline \multirow{2}{*}{ Red } & TS4 - S4 & 3.3049 & 8.4136 & 4.3660 & 0.5467 & 7.5004 & 5.0046 & 0.5169 \\
\hline & TS5 - S5 & 4.6018 & 9.0706 & 7.6909 & 10.1821 & 7.7993 & 7.1847 & 11.0570 \\
\hline \multirow{3}{*}{ Grey } & TB1 - B1 & 1.7974 & 4.5434 & 3.1003 & 2.5640 & 10.0028 & 30.7228 & 36.0144 \\
\hline & TB2 - B2 & 3.6353 & 3.4583 & 8.4761 & 7.3349 & 3.2836 & 60.9161 & 44.0555 \\
\hline & TB3 - B3 & 4.6214 & 4.1551 & 1.4548 & 5.8096 & 4.0877 & 3.0978 & 30.6121 \\
\hline \multirow{4}{*}{ Blue } & $\mathrm{TC} 1-\mathrm{C} 1$ & 7.6002 & 15.8421 & 11.9271 & 7.1891 & 13.4652 & 11.0601 & 7.5712 \\
\hline & $\mathrm{TC} 2-\mathrm{C} 2$ & 5.5595 & 8.6034 & 8.4969 & 6.3652 & 8.2074 & 7.9200 & 6.6324 \\
\hline & $\mathrm{TC} 3-\mathrm{C} 3$ & 9.0389 & 15.7453 & 11.7277 & 8.7845 & 15.7218 & 11.5254 & 6.8497 \\
\hline & $\mathrm{TC} 4-\mathrm{C} 4$ & 9.1131 & 9.7749 & 8.1743 & 9.7469 & 8.9848 & 8.6485 & 9.1265 \\
\hline \multirow{3}{*}{ Pink } & TP1 - P1 & 8.8794 & 7.8701 & 2.7047 & 9.6572 & 2.8979 & 2.5652 & 10.3180 \\
\hline & $\mathrm{TP} 2-\mathrm{P} 2$ & 7.9387 & 8.4594 & 7.0188 & 10.2581 & 8.6007 & 1.2523 & 10.6192 \\
\hline & TP3 - P3 & 8.8926 & 9.3496 & 9.4912 & 5.2409 & 9.5468 & 11.5214 & 5.1743 \\
\hline \multirow{2}{*}{ Yellow } & TY1 - Y1 & 11.2754 & 8.8329 & 3.9454 & 6.7239 & 10.1633 & 4.6523 & 6.7305 \\
\hline & TY2 - Y2 & 7.6979 & 6.6102 & 8.2188 & 9.0360 & 7.1302 & 9.1046 & 10.5031 \\
\hline \multirow{4}{*}{ Brown } & TBS1 - BS1 & 5.2359 & 8.1226 & 8.0461 & 10.9543 & 7.9175 & 7.8421 & 3.01459 \\
\hline & TBS2 - BS2 & 2.7954 & 8.8119 & 7.4291 & 8.04666 & 9.2519 & 7.7593 & 9.0909 \\
\hline & Mean & 6.0564 & 8.4962 & 7.3063 & 7.6913 & 8.5795 & 11.8482 & 12.5524 \\
\hline & SD & 2.7044 & 3.3136 & 2.9082 & 2.7667 & 3.4545 & 13.4767 & 11.4471 \\
\hline
\end{tabular}




\section{CONCLUSION}

Smartphone colorimetry is a suitable aid to objectify the colors of Batik fabrics. It is a simple, inexpensive, and reliable on-site analysis for nonexperts in the color matching process. The Batik fabric colors measured using the smartphone application Colorimeter were different from those obtained with the dedicated colorimeter device. However, the precision of the color measured by the smartphone was within the threshold of acceptability of color differences. As the color measurement is sensitive to the distance from the target and lighting conditions, further investigations can be carried out to provide accurate Batik classifications based on smartphone colorimetry.

\section{ACKNOWLEDGEMENT}

We would like to thank Thailand Office of Higher Education Commission for providing financial support under the Creative Economy Innovation Hub: Upper South Region, grant no. 13/2561. This research was financially supported by the new strategic research project (P2P), Walailak University, Thailand.

\section{REFERENCES}

[1] E. Krisnawati, N. Sunarni, L. M. Indrayani, A. N. Sofyan, and T. Nur, "Identity exhibition in Batik motifs of Ebeg and Pataruman," $S A G E$ Open, vol. 9, no. 2, pp. 1-7, 2019.

[2] N. Ding, J. Lv, and L. Hu, "Research on national pattern reuse design and optimization method based on improved shape grammar," Int. J. Comput. Intell. Syst., vol. 13, no. 1, pp. 300-309, 2020.

[3] L. Rafeah, "Identity exhibition in Batik motifs of Ebeg and Pataruman," Adv. Sci. Lett., vol. 23, no. 11, pp. 10859-10861, 2017.

[4] L. Thienny, "Defining the aesthetics of the Nyonyas' Batik sarongs in the straits settlements, late nineteenth to early twentieth century," Asian Stud. Rev., vol. 40, no. 2, pp. 173-191, 2016.

[5] C. Kumah, N. Zhang, R. K. Raji, and R. Pan, "Color measurement of segmented printed fabric patterns in Lab color space from RGB digital images," J. Text. Sci. Technol., vol. 5, no. 1, pp. 1-18, 2019.

[6] J. M. Jabar, A. I. Ogunmokun, and T. A. A. Taleat, "Color and fastness properties of mordanted Bridelia ferruginea B dyed cellulosic fabric," Fash. Text., vol. 7, no. 1, Jan. 2020, Art. no. 1.

[7] M. Matusiak and A. Walawska, "Important aspects of cotton color measurement," Fiber Text. East. Eur., vol. 18, no. 3, pp. 17-23, 2010.

[8] G. R. M. La Rosa, S. Pasquale, E. Pedulla, F. Palermo, E. Rapisarda, and A. M. Gueli, "Colorimetric study about the stratification's effect on color perception of resin composites," Odontology, vol. 108, no. 3 , pp. 479-485, 2020.

[9] L. C. Hoffman, D. L. van Schalkwyk, M. Muller, T. Needham, B. J. van Rensburg, and K. W. McMillin, "Carcass yields and physiochemical meat quality characteristics of Namibian gemsbok (Oryx gazella) as influenced by muscle, gender and age," Meat Sci., vol. 169, Nov. 2020, Art. no. 108208.

[10] B. N. Altay, V. Husovska, A. Pekarovicova, and P. D. Fleming, "Formulating Pantone colors by unused base inks, formulation software, and a spectrophotometer," Color Res. Appl., vol. 44, no. 6, pp. 910-916, 2019.

[11] E. C. Sabir and Y. Yesil, "Spectrophotometric color matching in melange fibre blends," Fibres Text. East. Eur., vol. 19, no. 5, pp. 125$128,2011$.

[12] F. Failisnur, S. Sofyan, A. Kasim, and A. Tuty, "Study of cotton fabric dyeing process with some mordant methods by using Gambier (Uncaria gambir Roxb) extract," Int. J. Adv. Sci. Eng. Inf. Technol., vol. 8, no. 4, pp. 1098-1104, 2018.

[13] P. Li et al., "The recovery of post-burn hypertrophic scar in a monitored pressure therapy intervention programme and the timing of intervention," Burns, vol. 4, no. 6, pp. 1451-1467, 2018.

S. G. Kandi, "The effect of spectrophotometer geometry on the measured colors for textile samples with different textures," J. Eng. Fiber. Fabr., vol. 6, no. 4, pp. 70-78, 2011.
[14] Verivide.com, "DigiEye FAQ," 2010. [Online]. Available: https://www.verivide.com/article/digieye-faq. [Accessed: 23-Mar2020].

[15] M. Matusiak, A. Walawska, and W. SybIlska, "Comparison of spectrophotometric and digieye color measurements of woven fabrics," Tekst. ve Konfeksiyon, vol. 27, no. 1, pp. 53-59, 2017.

[16] L. N. Lau, C. W. Kan, M. C. W. Yuen, and R. K. W. Lau, "Study of the correlation between solid colors measured by spectrophotometer and digiEye," Int. J. Comput. Internet Manag., vol. 19, no. sp1, pp. 3.1-3.6, 2011

[17] M. H. M. Salim, N. M. Ali, and S. A. M. Noah, "Mobile application on healthy diet for elderly based on persuasive design," Int. J. Adv. Sci. Eng. Inf. Technol., vol. 7, no. 1, pp. 222-227, 2017.

[18] R. Umar, I. Riadi, and G. M. Zamroni, "Mobile forensic tools evaluation for digital crime investigation," Int. J. Adv. Sci. Eng. Inf. Technol., vol. 8, no. 3, pp. 949-955, 2018.

[19] S. Y. Tan, H. Arshad, and A. Abdullah, "An efficient and robust mobile augmented reality application," Int. J. Adv. Sci. Eng. Inf. Technol., vol. 8, no. 4-2, pp. 1672-1678, 2018.

[20] Z. R. Mahayuddin and N. Mamat, "Implementing augmented reality (AR) on phonics-based literacy among children with autism," Int. J. Adv. Sci. Eng. Inf. Technol., vol. 9, no. 6, pp. 2176-2181, 2019.

[21] S. Cubero, F. Albert, J. M. Prats-Moltalban, D. G. Fernandez-Pacheco, J. Brasco, and N. Alexios, "Application for the estimation of the standard citrus color index (CCI) using image processing in mobile devices," Biosyst. Eng., vol. 167, pp. 63-74, 2018.

[22] K. Golicz, S. Hallett, R. Sakrabani, and J. Ghosh, "Adapting smartphone app used in water testing, for soil nutrient analysis," Comput. Electron. Agric., vol. 175, Aug. 2020, Art. no. 105532.

[23] Z. S. Fan et al., "Measurement of soil color: A comparison between smartphone camera and the Munsell color charts," Soil Sci. Soc. Am. $J .$, vol. 81, no. 5, pp. 1139-1146, 2017.

[24] S. Sumriddetchkajorn, K. Chaitavon, and Y. Intaravanne, "Mobile device-based self-referencing colorimeter for monitoring chlorine concentration in water," Sensors Actuators, B Chem., vol. 182, pp. 592-597, 2013.

[25] H. R. Hong and Y. I. Kim, "A mobile application for personal color analysis," Cogent Bus. Manag., vol. 6, no. 1, pp. 1-11, 2019.

[26] Z. Xiang, J. Zhang, and X. Hu, "Vision-based portable yarn density measure method and system for basic single color woven fabrics," $J$. Text. Inst., vol. 109, no. 12, pp. 1543-1553, 2018.

[27] D. C. Mulcare and T. J. Coward, "Suitability of a mobile phone colorimeter application for use as an objective aid when matching skin color during the fabrication of a maxillofacial prosthesis," $J$. Prosthodont., vol. 28, no. 8, pp. 934-943, 2019.

[28] I. Safarik, E. Baldikova, J. Prochazkova, and K. Pospiskova, "Smartphone-based image analysis for evaluation of magnetic textile solid phase extraction of colored compounds," Heliyon, vol. 5, no. 12, Dec. 2019, Art. no. e02995.

[29] C. Sirisathitkul, K. Ekmataruekul, Y. Sirisathitkul, and W. Noonsuk, "Smartphone colorimetry of fine-paste ware in Hindu-Buddhist rituals," Eur. J. Sci. Theol., vol. 16, no. 3, pp. 179-186, 2020.

[30] T. T. Wang et al., "A feasible image-based colorimetric assay using a smartphone RGB camera for point-of-care monitoring of diabetes," Talanta, vol. 206, Jan. 2020, Art. no. 120211.

[31] X. Li et al., "A smartphone-based bacteria sensor for rapid and portable identification of forensic saliva sample," Sensors Actuators, B Chem., vol. 320, Oct. 2020, Art. no. 128303 .

[32] D. Bas, "Sensitive and reliable paper-based glucose sensing mechanisms with smartphone readout using the: $\mathrm{L}^{*} \mathrm{a}$ *b* color space," Anal. Methods, vol. 9, no. 47, pp. 6698-6704, 2017.

[33] J. L. D. Nelis etal., "The efficiency of color space channels to quantify color and color intensity change in liquids, $\mathrm{pH}$ strips, and lateral flow assays with smartphones," Sensors (Switzerland), vol. 19, no. 23, Nov. 2019, Art. no. 5104.

[34] Research Lab Tools, "Lab tool apps," 2015. [Online]. Available: https://play.google.com/store/apps/details?id=com.colorimeter. [Accessed: 23-Mar-2020].

[35] T. M. Goodman, "International standards for color," in Color Design Theories and Applications, Netherlands: Woodhead Publishing Series in Textiles, 2012.

[36] E. H. Ismail, D. V. Dawson, and R. R. Maia, “A novel sample design for determining color compatibility between layered resin composite and vita shade guides," J. Esthet. Restor. Dent., vol. 32, no. 1, pp. 3442,2020 . 